\title{
PENERAPAN MODEL PEMBELAJARAN QUANTUM TEACHING BERBANTUAN SOFTWARE GEOGEBRA TERHADAP KEMAMPUAN PEMAHAMAN MATEMATIS
}

\author{
Windasari $^{1}$, Ichsan $^{2}$, Hodiyanto $^{3}$ \\ ${ }^{1,2,3}$ Program Studi Pendidikan Matematika, MIPATEK, IKIP PGRI Pontianak \\ Email: sariwinda640@gmail.com
}

\begin{abstract}
Abstrak
Tujuan dalam penelitian ini adalah untuk mengetahui kemampuan pemahaman matematis siswa yang diajarkan menggunakan model pembelajaran Quantum teaching pada materi koordinat kartesius kelas VIII SMP Negeri 1 Sambas. Metode yang digunakan dalam penelitian ini adalah metode eksperimen. Bentuk penelitian yang digunakan adalah eksperimen semu dengan rancangan postest-only control design. Populasi dalam penelitian ini adalah seluruh siswa kelas VIII SMP Negeri 1 Sambas. Pengambilan sampel menggunakan teknik cluster random sampling sehingga terpilih kelas VIIIC sebagai eksperimen 1 yaitu menggunakan model pembelajaran quantum teaching berbantuan software geoegbra dan kelas VIIIA sebagai kelas eksperimen 2 yaitu menggunakan model pembelajaran quantum teaching tanpa berbantuan software geogebra. Hasil penelitian menunjukkan bahwa hasil belajar siswa setelah diberikan model pembelajaran quantum teaching berbantuan software geogebra lebih baik daripada hasil belajar siswa setelah diberikan model pembelajaran quantum teaching tanpa berbantuan software geoegbra yaitu rata-rata nilai posttest kelas eksperimen 175,83 , termasuk dalam kategori baik sedangkan rata-rata nilai posttest kelas eksperimen 2 69,48, termasuk dalam kategori cukup.
\end{abstract}

Kata Kunci: Model Pembelajaran Quantum Teaching, Software Geogebra, Kemampuan pemahaman matematis.

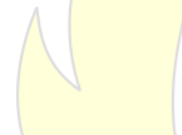

Abstract

The purpose of this study was determine the mathematical understanding ability of students taught using Quantum teaching learning models in the class VIII SMP Negeri I Sambas cartesian coordinate material. The method used in this research is the experimental method. The form of research used is quasi-experimental design with posttest-only control design. The population in this study were all class VIII students of SMP Negeri 1 Sambas. Sampling using cluster random sampling techniques so that selected class VIIIC as experimental class 1 is using quantum teaching learning model assisted by geogebra software and class VIIIA as experimental class 2 is using quantum teaching learning model without assisted by geogebra software. The result showed that student learning outcomes after being given a quantum teaching learning model assisted by geogebra software were better than student learning outcomes after being given a quantum teaching learning model without assisted by geogebra software namely the average posttest value of experimental class 1 75,83 included in the good category while the average experimental class 2 posttest value 69,48 included in the sufficient category. Test the difference in average student learning outcomes after using the quantum teaching model assisted by geogebra software and quantum teaching without assisted geogebra software it ca be concluded that there is a sigificant increase in results between the average scores in the experimental class 1 posttest and te average value in the experimental class posttest 2.

Keywords: quantum teaching learning model, geogebra software, mathematical understanding ability. 


\section{PENDAHULUAN}

Matematika berfungsi sebagai salah satu ilmu yang digunakan untuk mengkaji fenomena yang ada dalam kehidupan sehari-hari. Kenyataan yang sering terjadi selama ini, peserta didik menganggap matematika sebagai mata pelajaran yang sulit dan menakutkan. Salah satu hal yang memfaktori adalah karena kurangnya pemahaman peserta didik dalam memvisualisasikan materi secara abstrak. Hal inilah yang menjadi kendala bagi peserta didik, khususnya bagi peserta didik kelas VIII di SMP Negeri 1 Sambas, karena pola pikirnya belum seluruhnya terbentuk untuk memahami suatu permasalahan yang diberikan.

Kenyataannya, dari hasil studi dokumentasi dilapangan yang terjadi di kelas VIII SMP Negeri 1 Sambas diketahui bahwa perangkat pembelajaran matematika kelas VIII secara umum belum menggunakan model pembelajaran quantum teaching. Sebagian besar proses pembelajaran yang terdapat dalam Rencana Pelaksanaan Pembelajaran (RPP) masih menggunakan model pembelajaran biasa. Hal ini dikuatkan dengan hasil wawancara yang dilakukan peneliti pada saat pra observasi tanggal 20 April 2019 yaitu diperoleh informasi bahwa masih banyak dijumpai faktor rendahnya pemahaman siswa terhadap materi koordinat kartesius antara lain siswa terbiasa mempelajari konsepkonsep dan rumus-rumus matematika dengan cara menghafal tanpa memahami maksud, isi dan kegunaannya. Faktor lainnya, yaitu kebanyakan siswa memahami konsep yang baru tanpa didasari pemahaman mengenai konsep matematis sebelumnya. Hal ini menimbulkan efek yang tidak baik terhadap pemahaman matematis siswa, tidak hanya dilihat dari wawancara peneliti juga melihat dari data hasil nilai ulangan siswa yang diperoleh dari guru bidang studi matematika pada siswa kelas VIII di SMP Negeri 1 Sambas diperoleh hasil bahwa siswa mengalami kesulitan jika diminta untuk memahami soal sehingga berdampak pada sulitnya siswa dalam menyelesaikan soal.

Dalam penelitian ini yang dimaksud dengan pemahaman matematis adalah kemampuan dalam menyerap, mengingat, dan menerapkan konsep dalam penyelesaian masalah serta memperkirakan salah dan benarnya suatu konsep. Pemahaman matematis adalah hard skill yang paling mendasar yang harus dimiliki oleh peserta didik dalam mempelajari konsep matematika. Lemahnya pemahaman peserta didik khususnya dalam mempelajari matematika, berakibat pada sulitnya mereka dalam memahami konsep matematika yang lain. Matematika bersifat deduktif, terstruktur dan sistematis. Konsep dalam matematika sangat berkaitan satu dengan yang lainnya. Ada beberapa materi yang menjadi prasyarat terhadap materi yang lainnya, sehingga untuk memahami konsep matematika terlebih dahulu memahami memahami konsep prasyarat materi tersebut.

Pada kurikulum 2013 seharusnya dalam proses belajar mengajar guru berperan sebagai fasilitator dan moderator harus mampu mendesain pembelajaran yang interaktif dengan memberikan kesempatan kepada siswa untuk aktif menyumbangkan pemikirannya dalam proses belajar baik untuk diri sendiri maupun aktif membantu siswa lain dalam menafsirkan pemasalahan yang nyata namun lebih dari itu, guru harus memiliki beragam kompetensi untuk menunjang profesionalitas tugas dan perannya. Salah satu pembuktian dari kompetensi seorang guru ialah bagaimana ia mampu memandu dan menciptakan proses pembelajaran agar dapat mencapai target kompetensi yang hendak dicapai. Dengan pembelajaran yang menarik dan menyenangkan maka siswa akan lebih berminat dalam belajar. Namun, bukan hanya menarik minat siswa tetapi diharapkan juga akan berdampak pada hasil belajar siswa serta membuat siswa aktif dalam kegiatan pembelajaran. Agar pembelajaran menarik dan menyenangkan, perlu adanya solusi supaya siswa memperoleh kesempatan berinteraksi belajar sehingga pada akhirnya dapat diperoleh hasil belajar yang optimal yaitu dengan menggunakan model pembelajaran yang inovatif.

Oleh karena itu, diperlukan adanya suatu model pembelajaran berpusat pada siswa dan guru hanya sebagai fasilitator saja yang dapat diterapkan pada saat proses pembelajaran. Adapun model pembelajaran yang digunakan yaitu Quantum teaching. Model Quantum teaching yang berasas "Bawalah Dunia Mereka ke Dunia Kita" dan Antarkan Dunia Kita ke Dunia Mereka". Quantum teaching juga menyertakan segala kegiatan antara interaksi dan perbedaan yang memaksimalkan momen belajar. Menurut Deporter (2010: 34) Quantum teaching mempunyai kerangka rancangan belajar yang dikenal sebagai TANDUR: Tumbuhkan, Alami, Namai, Demonstrasi, Ulangi, dan Rayakan. Pengajaran Quantum terdiri dari dua kata "Quantum dan Pengajaran" kata pengajaran Quantum dipinjam dari fisika, yang mengasumsikan bahwa sifat-sifat baru muncul ketika keberadaannya tergabung atau terhubung. Karenanya total keseluruhan bagian-bagiannya. Setiap bagian Quantum memiliki potensi ganda mengenai waktu dan kapasitas dalam mempengarui dunia pembelajaran. Hubungan non-liniar dan ada hubungan sebab akibat yang saling menguntungkan. Dalam Quantum, sistem menunjukkan variasi, kejelasan, kompleksitas, kausalitas dan hubungan timbal balik yang mencerminkan perubahan kualitatif ke perubahan kuantitatif. (Bahaddin and Yusuf, Rumapea 2017) [121]. Jadi, definisi pengajaran Quantum adalah mengubah bermacammacam interaksi menjadi bermakna dalam kegiatan pembelajaran.

Selain itu, pada penelitian ini peneliti menggunakan model pembelajaran Quantum teaching yang telah dimodifikasi dengan software geogebra yang mana aplikasi geogebra digunakan sebagai alat bantu dalam pembelajaran matematika yang bertujuan untuk memudahkan pemahaman dan penerimaan informasi dalam proses pembelajaran khususnya pada materi koordinat kartesius. Selain itu, software geogebra dapat memberikan pengalaman visual kepada peserta didik dalam berinteraksi dengan konsep geometri melalui tampilan yang variatif dan menarik serta kemudahan dalam menggambarkan titik, ruas, garis dan sebagainya diharapkan dapat meningkatkan minat dan kreativitas belajar (Hohenwarter \& Fuchs, Supriady: 2015: 1). 
Program ini dapat dimanfaatkan untuk meningkatkan pemahaman peserta didik terhadap konsep yang telah dipelajari maupun sebagai sarana untuk memperkenalkan atau mengkonstruksi objek baru.

Menurut NCTM (2000), Pendidikan yang baik adalah usaha yang berhasil membawa siswa kepada tujuan yang ingin dicapai yaitu agar bahan yang disampaikan dipahami sepenuhnya oleh siswa. Demikian pula, pemahaman matematis merupakan landasan penting untuk berpikir dalam menyelesaikan persoalan-persoalan matematika maupun masalah kehidupan nyata. Selain itu, kemampuan pemahaman matematis sangat mendukung pada pengembangan kemampuan matematis lainnya, yaitu komunikasi, pemecahan masalah, penalaran, koneksi, representasi, berpikir kritis dan berpikir kreatif matematis serta kemampuan matematis lainnya (Fitriatien, 2019). Kemampuan pemahaman matematis dalam penelitian ini merupakan kemampuan seseorang yang meliputi kemampuan mendefinisikan konsep secara verbal dan tulisan, mengidentifikasi contoh dan non contoh, menggunakan diagram dan simbol untuk mempresentasikan suatu konsep, mengubah suatu bentuk representasi ke bentuk representasi lainnya.

Dengan visualisasi konsep matematika, khususnya materi koordinat kartesius diharapkan akan mempermudah peserta didik dalam menambah kemampuan pemahamannya. Apalagi di SMP Negeri 1 Sambas belum pernah dilakukan uji coba penggunaan media geogebra. Jadi, tujuan penelitian ini adalah untuk mengetahui kemampuan pemahaman matematis siswa dengan menggunakan media berbantuan software geogebra sebagai alat bantu dalam pembelajaran matematika pada kelas eksperimen 1 dalam materi koordinat kartesius.

\section{METODE}

Metode dalam penelitian ini adalah metode penelitian eksperimen. Bentuk yang digunakan dalam penelitian ini adalah eksperimen semu/quasi experimental design. Rancangan yang digunakan dalam penelitian ini adalah postest-only control design:

Tabel 1. Rancangan Penelitian Postest-Only Control Design

\begin{tabular}{ccc}
\hline Kelas & X & Post-test \\
\hline Eksperimen 1 & $X_{1}$ & $P_{1}$ \\
Eksperimen 2 & $X_{2}$ & $P_{2}$ \\
\hline
\end{tabular}

Keterangan:

$\begin{array}{ll}\text { Ke } 1 & \text { : Kelas Eksperimen } 1 \\ \text { Ke } 2 & \text { : Kelas Eksperimen } 2 \\ X_{1} & \text { : Perlakuan (treatment) yang diberikan pada } \\ & \text { kelas eksperimen } 1 \text { dengan model }\end{array}$

p-ISSN 2088-3021

$e$-ISSN 2598-8077

pembelajaran quantum teaching berbantuan software geogebra

$X_{2} \quad$ : Perlakuan (treatment) yang diberikan pada

kelas eksperimen 2 dengan model

pembelajaran quantum teaching tanpa

berbantuan software geogebra

$P_{1} \quad$ : Postest pada kelas eksperimen 1

$P_{2} \quad$ : Postest pada kelas eksperimen 2

Populasi dari penelitian ini adalah semua kelas VIII SMP Negeri 1 Sambas. Sampel penelitian ditentukan dengan menggunakan teknik cluster random sampling. sampel pada penelitian ini adalah kelas VIIIC sebagai kelas eksperimen 1 dan kelas VIIIA sebagai kelas eksperimen 2. Teknik pengumpulan data pada penelitian ini menggunakan pengukuran yang dilakukan pada hasil jawaban siswa dalam mnyelesaikan soal-soal posttest.

Instrumen yang digunakan dalam penelitian ini adalah rencana pelaksanaan pembelajaran (RPP), lembar kerja siswa (LKS), tes kemampuan pemahaman matematis. Tes tersebut berbentuk essai terdiri atas 7 soal pemahaman matematis. Soal tes dikembangkan oleh peneliti dan divalidasi oleh validator.

\section{HASIL DAN PEMBAHASAN}

Berdasarkan hasil pengumpulan data selama penelitian di SMP Negeri 1 Sambas diperoleh hasil belajar siswa, yaitu nilai akhir (posttest) kemampuan pemahaman matematis. Adapun data tersebut akan dibahas sebagai berikut.

Tabel 2. Data Tes Kemampuan Pemahaman Matematis

Kelas Eksperimen 1 dan Kelas Eksperimen 2

\begin{tabular}{ccc}
\hline \multirow{2}{*}{ Keterangan } & \multicolumn{2}{c}{ Posttest } \\
\cline { 2 - 3 } & Eksperimen 1 & Eksperimen 2 \\
\hline Jumlah & 2275 & 2015 \\
Rata-rata & 75,83 & 69,48 \\
Max & 95 & 85 \\
Min & 55 & 50 \\
\hline
\end{tabular}

Dari tabel 2. Diperoleh nilai rata-rata posttest kemampuan pemahaman matematis sebesar 75,83 dimana nilai maksimum posttest kelas eksperimen 1 adalah 95 dan nilai minimum adalah 55. Nilai rata-rata posttest kemampuan pemahaman matematis sebesar 69,48 dimana nilai maksimum posttest kelas eksperimen 1 adalah 85 dan nilai minimun adalah 50 .

Tabel 3. Data Uji Normalitas Kemampuan Pemahaman Matematis

Kelas Eksperimen 1 dan Kelas Eksperimen 2

\begin{tabular}{ccc}
\hline Keterangan & Eksperimen 1 & Eksperimen 2 \\
\hline Jumlah siswa & 30 & 29 \\
$\chi_{\text {hitung }}^{2}$ post-test & 7,65 & 6,95 \\
$\chi_{\text {tabel }}^{2}$ post-test & 9,49 & 7,81 \\
Kesimpulan & Normal & Normal \\
\hline
\end{tabular}


Berdasarkan tabel 3. Diatas $\chi_{\text {hitung }}^{2}$ post-test eksperimen $1=7,65<\chi_{\text {tabel }}^{2}$ post-test $=9,49$, sehingga keputusan uji $H_{0}$ diterima, dan data berdistribusi normal. $\chi^{2}$ hitung post-test eksperimen $2=$ $6,95<\chi_{\text {tabel }}^{2}$ post-test $=7,81$, sehingga keputusan uji $H_{0}$ diterima, dan data berdistribusi normal.

Setelah data tersebut berdistribusi normal maka dilakukan pengujian hipotesis dan uji-t, diperoleh kemampuan pemahaman matematis $t_{\text {hitung }}$ sebesar 2,139 dan $t_{\text {tabel }}$ sebesar $1,672(\alpha=5 \%$ dan $\mathrm{dk}=57)$ maka $H_{\text {o }}$ ditolak. Sehingga diperoleh kesimpulan bahwa kemampuan pemahaman matematis setelah diberikan perlakuan dengan model pembelajaran Quantum teaching berbantuan software geogebra dan model pembelajaran Quantum teaching tanpa berbantuan software geogebra adalah homogen.

Mengacu pada pembahasan mengenai proses pembelajaran model Quantum teaching berbantuan software geogebra tersebut, lebih lanjut akan dibahas mengenai kemampuan pemahaman matematis yang berkaitan dengan sub-sub masalah sebagai berikut: (1) kegiatan post-test pada penelitian ini dilakukan untuk mengetahui kemampuan pemahaman matematis siswa pada materi koordinat kartesius di kelas VIIIC sebagai kelas eksperimen 1 di SMP Negeri 1 Sambas setelah diterapkan model pembelajaran Quantum teaching berbantuan software geogebra. Berdasarkan data yang diperoleh dari pengolahan data menggunakan Microsoft Excel dapat diketahui nilai rata-rata post-test 75,83 dengan kategori baik.

Sebagian besar proses pembelajaran yang terdapat dalam Rencana Pelaksanaan Pembelajaran (RPP) menggunakan model pembelajaran Quantum teaching berbantuan software geogebra. Dalam hal ini saaat proses belajar mengajar, terlihat guru menyampaikan dan menjelaskan materi pembelajaran dengan menggunakan langkah dari model Quantum teaching yaitu TANDUR dan siswa masing-masing menggunakan 1 buah komputer selama pembelajaran dan siswa diberikan lembar kerja siswa (LKS) yang sudah dilengkapi dengan materi, contoh soal dan latihan. Kemudian siswa diminta untuk memahami materi didalam LKS tersebut. Setelah siswa memahami materi siswa diminta bersama-sama dengan guru menjawab dan mengerjakan latihan soal agar siswa paham apa yang dimaksud dan jika jawaban siswa benar maka guru bersama siswa memberikan penghargaan dalam bentuk tepuk tangan dalam materi koordinat kartesius. Hal tersebut dilakukan agar siswa menjadi aktif dan tidak bosan selama mengikuti pembelajaran berlangsung, melalui model pembelajaran Quantum teaching berbantuan software geogebra ini mampu membuat siswa belajar dengan berpikir kritis, aktif dalam pembelajaran, mengajarkan siswa mengaitkan hal yang berbentuk teori menjadi kenyataan. Maka daripada itu dapat membantu siswa dalam proses belajar secara aktif; (2) kegiatan post-test pada penelitian ini dilakukan untuk mengetahui kemampuan pemahaman matematis siswa pada materi koordinat kartesius di kelas VIIIA sebagai kelas eksperimen 2 di SMP Negeri 1 Sambas setelah diterapkan model pembelajaran Quantum teaching tanpa berbantuan software geogebra. Berdasarkan data yang diperoleh dari pengolahan data menggunakan Microsoft Excel dapat diketahui nilai rata-rata post-test yaitu 69,48 dengan kategori cukup.

Hal ini dikarenakan siswa mempelajari materi koordinat kartesius tanpa berbantuan software geogebra. Model pembelajaran yang dimaksud adalah model pembelajaran yang dapat membantu siswa menyelesaikan masalah atau soal yang diberikan guru tapi dalam hal ini tanpa mengaitkan dengan kenyataan dilapangan atau praktek. Pada saat proses belajar mengajar guru menyampaikan materi dengan menggunakan kerangka TANDUR dan siswa diberikan lembar kerja siswa (LKS) yang sudah dilengkapi dengan materi, contoh soal dan latihan. Kemudian siswa diminta untuk memahami materi didalam LKS tersebut. Setelah siswa memahami materi siswa diminta bersama-sama dengan guru menjawab dan mengerjakan latihan soal agar siswa paham apa yang dimaksud dan jika jawaban siswa benar maka guru bersama siswa memberikan penghargaan dalam bentuk tepuk tangan dalam materi koordinat kartesius.

Setelah membahas contoh soal bersama, siswa juga diminta untuk menyelesaikan soal latihan yang tertera dalam LKS dimana siswa diminta untuk menjawab pertanyaan yang telah disediakan. Peran guru yaitu berkeliling mengecek siswa dalam mengerjakan soal jika siswa masih kebingungan maka guru memberikan arahan untuk menyelesaikan soal tersebut. Pada saat siswa mengerjakannya peneliti mengecek jawaban siswa ada beberapa siswa yang masih bingung dalam menjawab maka peneliti memberikan arahan agar siswa paham dalam menyelesaikannya, dan ada pula siswa yang sudah paham dalam mengerjakannya. Setelah siswa selesai mengerjakan soal latihan tersebut peneliti meminta salah satu siswa maju kedepan untuk mempresentasikan hasilnya dan setelah mempresentasikan maka peneliti menerangkan kembali agar siswa memahami materi yang sedang dipelajari; (3) berdasarkan uji hipotesis menggunakan uji-t, hasil penelitian sesuai dengan hipotesis penelitian, yaitu diperoleh kemampuan pemahaman matematis adalah $t_{\text {hitung }}$ sebesar 2,139 dan $t_{\text {tabel }}$ sebesar 1,672 ( $\alpha=5 \%$ dan $\mathrm{dk}=57$ ).

Dengan demikian maka diperoleh kemampuan pemahaman matematis siswa setelah diberi perlakuan dengan model pembelajaran Quantum teaching berbantuan software geogebra lebih baik daripada menggunakan model pembelajaran Quantum teaching tanpa berbantuan software geogebra pada materi koordinat kartesius dikelas VIII SMP Negeri 1 Sambas. Hal ini sesuai dengan penelitian sebelumnya Dervika (2017) dari penelitian yang sudah dilakukan, dapat disimpulkan bahwa pembelajaran dengan model Quantum Teaching berbantuan media video hasil belajar siswa menjadi baik. Selain itu juga dapat dilihat dari keberhasilan belajar siswa memberikan respon atau tanggapan yang positif pada penerapan model 
pembelajaran Quantum Teaching pada materi teorema pythgoras. Penelitian Irawati (2017) berdasarkan hasil penelitian dan pembahasan maka dapat disimpulkan bahwa pelaksanaan pembelajaran matematika menggunakan model pembelajaran Quantum Teaching dapat meningkatkan hasil belajar biologi kelas XI IPA 2 SMA Negeri 2 Bengkulu, hasil belajar yang meningkat terutama dalam aspek kognitif.

Maka peneliti dapat menyimpulkan bahwa penerapan model Quantum teaching berbantuan software geogebra dapat mengatasi pemahaman matematis sehingga siswa dapat menguasai materi terutama pada materi koordinat kartesius. Dengan demikian, selama pembelajaran menggunakan model Quantum teaching berbantuan software geogebra terdapat peningkatan yang cukup signifikan antara nilai posttest kelas eksperimen 1 yaitu 30 orang siswa dan kelas eksperimen 2 yaitu 29 orang siswa di SMP Negeri 1 Sambas.

\section{PENUTUP}

\section{Simpulan}

Berdasarkan hasil analisis data dan pembahasan, maka secara umum dapat disimpulkan bahwa kemampuan pemahaman matematis siswa yang diberikan model pembelajaran Quantum teaching berbantuan software geogebra lebih baik daripada siswa yang diberikan model pembelajaran Quantum teaching tanpa berbantuan software geogebra di kelas VIII SMP Negeri 1 Sambas.

Saran

Penelitian ini bisa digunakan untuk pengembangan penelitian selanjutnya.

\section{DAFTAR PUSTAKA}

Creswell, J W. 2016.. Research Desgin. Jakarta: Pustaka Belajar.

DePorter, B dkk. 2010. Quantum Teaching: Mempraktikkan Quantum Learning di Ruangruang Kelas. Bandung: Kaifa.

Dervika, S. 2017. Implementasi Pembelajaran Quantum Teaching Berbantuan Media Video Terhadap Pemecahan Masalah Matematis Siswa Dalam Materi Teorema Pyhtgoras Ditinjau Dari Gaya Belajar Siswa Kelas VIII SMP IT Al Mumtaz. Pontianak. Skripsi pada IKIP-PGRI Pontianak: Tidak diterbitkan.

Fitriatien, S. R. (2019). Error description of the first year student in aljabar problems. Math Didactic: Jurnal

Pendidikan Matematika.

https://doi.org/10.33654/math.v5i2.655

Hendriana, H dkk. 2017. Hard Skills and Soft Skills. Bandung: PT.Revika Aditama.
Hodiyanto dan Danar S. 2019. Geometer's Sketchpad (GSP) dan Pemahaman Konsep Geometri Analitik bidang. Jurnal Kreano, 10 (2).

Irawati, S dan Anisa P J. 2017. Penerapan Model Quantum Teaching Untuk Meningkatkan Hasil Belajar Biologi Kelas XI IPA 2 SMA Negeri 5 Bengkulu. Jurnal Pendidikan Eksakta. Volume 1, Nomor 2.

National Council Of Teacher Of Mathematics (NCTM). 2000. Reston: (VA: Authur. http://educare.efkipunla.net.

Nur, M I. 2016. Pemanfaatan Program Geogebra Dalam Pembelajaran Matematika. Jurnal Pendidikan Matematika, 5 (1).

Rumapea, G. 2017. Application of Quantum Teaching Learning Model to Improve Student Learning Outcomes. International Journal Of Novel Research In Education and Learning: 4(2) 121.

Suprihady, D. 2015. Aplikasi Geogebra Dalam Pembelajaran Geometri Bidang Makalah IF2123 Aljabar Geometri-Informatika ITB[Online]. Tersedia http://Informatika.stei.itb.ac.id/rinaldi.munir/AljabarGeometri/2015/MakalahIF2123-2015-108-pdf. 
Windasari1 ${ }^{1}$ Ichsan², Hodiyanto ${ }^{3}$ : Penerapan Model Pembelajaran Quantum Teaching Berbantuan Software Geogebra Terhadap Kemampuan Pemahaman Matematis 